\title{
Exploration of the Application of Positive Psychology in the Field of Psychological Health Education
}

\author{
Yifan Wang \\ Baoshan University, Baoshan, 678000, China
}

\begin{abstract}
Keywords: Positive psychology, Psychological health education for college students, Psychological measurement, Psychological intervention
\end{abstract}

\begin{abstract}
Positive psychology is the latest research achievement of contemporary psychology. It profoundly analyzes the internal and external positive strength and behavioral ideology and moral quality rooted in human being, paying more attention to the development of the survival issue of human being and the development of psychological health education. It is hoped that this paper can take college students who are in puberty and in the transitional phase of psychological maturity as the research subject and solve their existing negative psychological problems with theory analysis, research and study and scientific psychological health education method so as to prove that the value of the application of positive psychology in the field of psychological health education
\end{abstract}

\section{Introduction}

Since 1980s, China has been carried out psychological health education in colleges. Its function was dedicated to the prevention and treatment for the psychological health problems of college students, however, in fact the psychological health education back then was inclined to functionally solve students' problems, yet ignore the actual demands of most of students on the development of psychological health, and therefore it did not realize the fundamental function for education. The arise of positive psychology just is a remedy for this problem. It pays close attention to the psychological development and psychological health, it therefore breaks through the bottle neck of psychological health education in colleges and provides a new angle and platform for the continuing development, which has a substantial potential for study.

\section{The Relevant Theories of Positive Psychology}

Positive psychology has other two names in Chinese, both meaning positive psychology. It is a psychological study theory which is newly getting popular in America. Positive psychology is the process of formation of good qualities by taking the actual potential of people_-constructive strength and virtues in nature, as a starting point and advocating people to face all psychological problems with a positive mental attitude. It can be applied to those people who have psychological problems and people who have certain talents, yet their potential need to be further exploited ${ }^{[1]}$.

\section{The Research and Analysis on the Psychological Health Education for College Students}

Currently, the psychological health education for students of colleges in China is not complete. Many colleges have been exploring the reasonable approach for psychological health education because the psychological problems of college students in puberty involve a variety of aspects, therefore it would be a long way to solve it. In order to study the current status of college students' psychological health in China, this paper also conducted study and an analysis, with the hope to find out the reason for the problems.

\section{Research Object}

The object of this research is the students of four colleges. The sample size is 300 people and the study method is questionnaire survey. 300 questionnaires were handed out and 280 were collected 
back. And there were 255 effective questionnaires (120 questionnaires from male students and 135 questionnaires from female students). The effective rate of questionnaires was $81 \%$

\section{Research Method and Tools}

The research method was mainly the distribution and collection of questionnaires at site, also along with on-the-spot interviews with specific questions. The research tool was mainly based on Research in the Status of Psychological Health Education for College Students to select the questions for the questionnaire, which ensured the scientific basis for the research.

\section{Analysis of Research Result}

This paper extracts two top questions from the questionnaire as the analysis focus, as showed in table 1 and table 2.

Table 1.

\begin{tabular}{|l|c|c|}
\hline \multicolumn{3}{|c|}{ Question: How do you face troubles and pressure? } \\
\hline Options & $\begin{array}{c}\text { Male } \\
\text { Students }\end{array}$ & $\begin{array}{c}\text { Female } \\
\text { Students }\end{array}$ \\
\hline $\begin{array}{l}\text { 1. Confiding to and talking with good and intimate } \\
\text { friends }\end{array}$ & 40 & 53 \\
\hline 2. Communicating with elders for solutions & 8 & 14 \\
\hline 3. Suffering it on your own and not to speak out & 62 & 60 \\
\hline 4. Asking help from psychological counseling & 10 & 8 \\
\hline
\end{tabular}

Table 2.

\begin{tabular}{|l|c|c|}
\hline Question: On what condition, you will ask psychological counseling for solutions to the problems \\
\hline Options & $\begin{array}{c}\text { Male } \\
\text { Students }\end{array}$ & $\begin{array}{c}\text { Female } \\
\text { Students }\end{array}$ \\
\hline 1. Having psychological problems & 32 & 46 \\
\hline $\begin{array}{l}\text { 2. Asking psychological counseling even if without psychological } \\
\text { problems }\end{array}$ & 5 & 9 \\
\hline 3. Never Ask psychological counseling & 83 & 80 \\
\hline
\end{tabular}

It is not hard to find out from the extracted twp problems in above table 1/2 that most college students are stilling unwilling to or do not believe in asking for psychological counseling. Even worse is that some students will get into a more isolated mental state just as they encounter psychological problems and are not willing to share their psychological problems with others or seek the solution for their problems. And in the interviews for students, it is found that some students think that asking psychological counseling would means that you have psychological problems, which is a shameful thing and they will be despised by other students. Some students also think that the psychological health education carried out by colleges does not work in solving problems and is not helpful for them so that they get much less interested in caring about the psychological courses promoted by colleges. The reality is indeed like this. In all of the 4 colleges in this research, the psychological health education is just optional course. Among 300 students in this research, only 51 would select this optional course and the reasons would be just out of curiosity or easy to get the credit and so on. They do not hope to solve their existing problems through this. It explains that the psychological health education in colleges in China is deviated with regard of concept and direction. It's education mode is limited and fails to motivate students' enthusiasm for participation, more importantly, the students in China do not believe in the significance of psychological health education on their life and growth, therefore it is rather difficult for colleges in carrying out psychological health education ${ }^{[2]}$ 


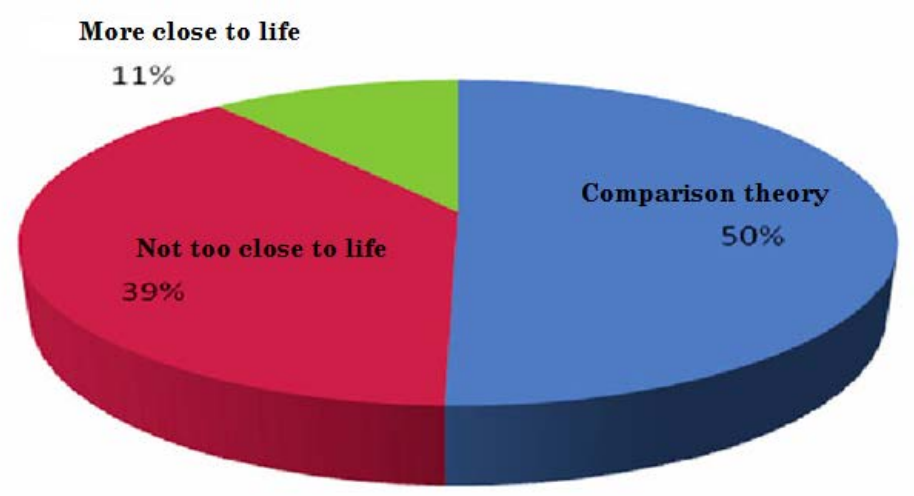

Fig. 1. The research result of college students: How do you perceive the psychological health education course in school

\section{Study Standpoint of Positive Psychology based on College Students' Psychological Problems}

From the perspective of positive psychology to look at the research result, it is found that nowadays the psychological health education in colleges puts more emphasis on people's mistakes and weakness and hopes to find the problems on these levels and find the corresponding solutions, which is just the " negative psychological education method" as mentioned in this paper. But, in fact, what colleges should do at present is to adopt positive psychology, pay active attention to people and build people's advantages and strengths. In other words, colleges should correct their thought on the solution to psychological problems of students, which should not take psychological health education as a service education to cure illness or health recovery, instead should pay attention to people's growth, education, games wisdom and even love and look at the people's inborn positive qualities positively and scientifically. Only in this case, it can give full play to the tremendous function of positive psychology.

\section{Application Method of Positive Psychology in the Colleges' Psychological Health Education}

First, it must be clearly confirmed that positive psychology is a mingled process of thoughts and behaviors to nature the psychological quality. It can be regarded as a process of psychological experience because there is an argument in positive psychology that the accurate and effective way of education and training is to improve and develop an individual's positive character, strength and quality through an individual's positive experience. Therefore, this paper interprets several positive psychology education methods that can be applied in nowadays colleges' psychological health education from a scientific point of view.

\section{Psychological Measurement}

Psychological measurement the description process of psychological characteristic behavior based on the measurement and evaluation of psychological phenomenon. It can make a quantified explanation for people's psychological behavior and body movement. In positive psychology, psychological measurement can be served for psychological health education and select and evaluate students' actual psychological health status objectively so as to improve the implementation of psychological health education, therefore it can be also called positive psychological measurement. Positive psychological measurement can be divided into two forms: the measurement of subjective well-being and measurement of power of personality.

Each one's subjective thinking towards the understanding of happiness is different. In October, 2010, China Youth News conducted a random interview on the campuses of Tsinghua University, Beijing Foreign Studies University, People’s University, Communication University of China and Minzu University of China. Among the 500 female students being interviewed, near half of them thought that happiness was the realization of self-value, while $23 \%$ of the female students thought 
that happiness was to establish a healthy and happy family. Less than $10 \%$ of them thought happiness was to make yourself and others happy, to have some children or chase your dream and so on. When they were asked about the factors affecting happiness, $48 \%$ of the female students put health on the top, and family, career, love and friends came to the second to the fifth. Near $60 \%$ of them put money at the last. But in the interview, one female student also said:” although I hate to admit it, money exactly can influence my happiness in life, which is an objective fact, yet it is not the most important factor that affects my happiness".

Subject well-being is to ask people to make an evaluation on their life concerning cognition and emotion. It can also be the comprehensive evaluation of life. Therefore, colleges' psychological health education should establish the satisfaction with life scale and well-being scale in the course, through which to measure students' subjective well-being an guide students to seek methods for improving their social relations, relation with friends and elders with a positive mentality so as to enhance their subjective well-being. In other words, it is to make oneself to recognize his current mentality and life through positive socializing and affective interaction. For Chinese, the expression of affection is rather reserved. The subjective well-being education based on positive psychology guide students to bravely take the first step to express their love to someone they like, to make a frank and open public speech and thank the people explicitly and so on. All of these are advantageous methods for the improvement of college students' individual personality. When one's subjective well-being is improves, his psychological state will also become healthier.

Table 3. Satisfaction with Life Scale based on Subjective Well-being

\begin{tabular}{|c|}
\hline Satisfaction with Life Scale \\
\hline $\begin{array}{l}1 \text { In most cases and from most aspects, my life is very close to my ideal } \\
2 \text { My life status is very good } \\
3 \text { I am very satisfied with my life } \\
4 \text { So far, I have obtained what I want in my life } \\
5 \text { If my life started over, I would not want to change anything }\end{array}$ \\
\hline 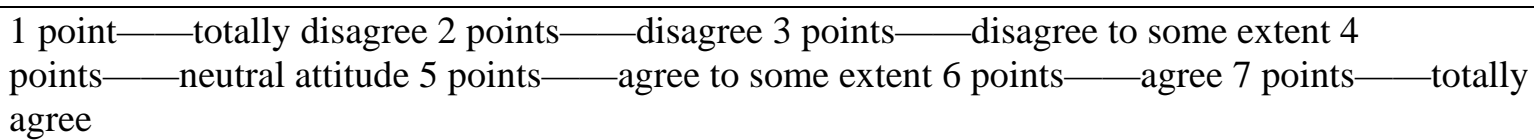 \\
\hline
\end{tabular}

\section{Positive Psychological Intervention}

Meanwhile, it can also adopt positive psychological intervention in colleges’ psychological health education. Such education method is also based on positive psychology, which is also called happy intervention. In America, professor $\mathrm{N}$ - Peseschkian believes that people should have two basic abilities, cognitive ability and love ability. These two abilities in theory open up infinite possibilities in life for people, but they also need to be differentiated and developed from people's other abilities in life such as logical ability, cleaning ability, ability to exercise manners, frugality ability and so on, while the ability to love natures people's patience, communication, trust, hope and belief. When one has psychological problem, cognitive ability and love ability will be prohibited so that people will step into a seclusion state. Therefore, it is necessary to carry out positive psychological intervention to adjust college students who happen to be in the phase of developing cognition of society and desiring to be loved while they are also the people who are prone to psychological problems.

Based on psychological intervention theory, the psychological health education method proposed by this paper is called " 5 -phase therapy". This method can realize the treatment and intervention to college students' psychological problems and give them correct ideological value and it has 5 specific steps in its procedure.

Observation Phase

In this phase, it is to observe students' behavior so as to distinguish their possible psychological problems. Psychological consultants will propose the guiding method for helping students based on this and divide students' actual reaction and optional action. For example, in the scenario of conflict, where, when, to whom and under what condition, students will have unpleasant emotion? In 
observation phase, it is to instill students with such ideas that make students calm under special conditions and thing more thoroughly, which of course is a rather ideal design and needs a series of education implementation to follow up.

\section{Research Phase}

In research phase, it purely takes students as the center and distinguishes their behaviors, from which inspect the possible positive psychological qualities and negative psychological qualities. In this case, it can acquire a rather comprehensive psychological state of one student so that it is helpful to implement education means in next phase, while identification subject is students' actual ability as mentioned above.

\section{Occasional Encouragement Phase}

The priority in this phase lies in changing the psychological pattern to which students are accustomed. It includes communication with people, behavior of self-thinking and so on. The purpose for doing it is to change students' old attitude so that they can improve their trust on others. It is all affirmative in encouragement phase, which gives up the inherent negative psychological therapy, namely criticizing, while students have psychological problems, instead it encourages him from the good side of his whole behavior so as to enhance his positive qualities and tries to eliminate the negative effects brought by traditional negative psychology for students as much as possible.

\section{Language Expression Phase}

This phase emphasizes communication. Psychological consultants should be clear that when students have psychological problems, to a large extent, it is because they have a problem in communicating with others. Therefore, the key to solve students' psychological problems and conflicts is the honesty, trust and manners from actual abilities. In this phase, consultants should establish a psychological mutual assistance platform for college students with "honest and manners" as the core. Through this platform, it is to increase the opportunities for students to participate in group activity and psychological activity and nature their positive emotion with actual experience and make students to realize communication with others in and out of classes and form a self-help and mutual assistance network so as to help students to improve their ability of self-cognition and self-regulation.

\section{Expanding Target Phase}

In the last phase, it is to help students to find their life goals to the greatest extent so as to solve their limitation of vision and psychological limitation of their goal boundary while they have psychological problems. Psychological consultants should let students experience totally fresh targets that they have never tried before instead of being limited in the targets that students have not realized. It is to expand students' horizon and stimulate their curiosity so as to reach the target of adjusting their exertion of positive potential ${ }^{[3]}$.

\section{Summary}

Positive psychology can improve human being's living quality and keep people far away from negative mentality so that they will look forward to the glorious in future. It has a profound practical significance in implementing psychological health education based on positive psychology. It is substantially helpful for cultivating college students with strong psychological quality to become the main force in the development of country in future. It is worth of deep study and extensive promotion in other social fields beyond colleges.

\section{References}

[1] Qi Zhou, Study on Psychological Health Education for College Students from the Perspective of Positive Psychology. Hunan Normal University,2013.13-20.

[2] Mei Peng, Research in College Students' Psychological Health Education from the Perspective of Positive Psychology. Heilongjiang University,2014.20-22. 
[3] Fang Liu. Study over China' College Students' Psychological Health Education from the Perspective of Positive Psychology. Zhengzhou University,2014.33-42. 